Psychology of Language and Communication 2017, Vol. 21, No. 1

DE GRUYTER

OPEN

DOI: $10.1515 /$ plc-2017-0012

\author{
ANABELA MALPIQUE ${ }^{12}$, ANA MARGARIDA V. VEIGA SIMÃO², \\ LOURDES MARIA B. FRISON ${ }^{3}$ \\ ${ }^{1}$ Murdoch University \\ ${ }^{2}$ University of Lisbon \\ ${ }^{3}$ Pelotas Federal University
}

\title{
SELF-REGULATED STRATEGIES FOR SCHOOL WRITING TASKS: A CROSS-CULTURAL REPORT
}

\begin{abstract}
We investigated cross-cultural differences in ninth-grade students' reported use of self-regulated strategies for writing. We assessed 12 self-regulated strategies for writing tapping environmental, behavioural, and personal self-regulated processes. Seven hundred and thirty-two Portuguese and Brazilian students in transition to high school $\left(M_{a g e}=14.3\right.$; 372 male and 306 female) from mainstream urban schools reported on their use of the strategies. Statistical analyses included a multivariate analysis of variance (MANOVA) with 12 dependent variables (self-regulated strategies for writing) and 2 between-subjects variables (country and gender). There were significant main effects for country with medium effect sizes and statistically significant small effect sizes for gender main effects. All-male and all-female comparisons indicated significant differences and medium effect sizes within gender groups. The majority of the differences tapped personal self-regulated strategies. Taken together, these findings suggest that initiating and controlling writing may be a contextualised bounded process.
\end{abstract}

Key words: self-regulation, writing-strategies, context

\section{Introduction}

Becoming an expert writer is a developmental process that requires high levels of personal regulation and strategic behaviour (Bereiter \& Scardamalia, 1987; Zimmerman \& Risemberg, 1997). Strategic processing is necessary for developing proficiency in any field of study (Alexander, Graham, \& Harris,

Address for correspondence: Anabela Malpique, School of Education, Murdoch University, 90 South St, Murdoch WA 6150, Australia. E-mail: anabela.malpique@gmail.com 
1998) and fundamental in a highly complex system of correlated processes, such as text composing. A good strategy user is a student who identifies the most suitable strategies to use for a particular task and purpose, knows how to apply those strategies more effectively, and recognises the time and place to use them (Weinstein, Husman, \& Dierking, 2000).

Several authors highlight the importance of understanding how students self-regulate school writing tasks as a way to substantiate effective writing instruction (Graham, MacArthur, \& Fitzgerald, 2013). Zimmerman and Risemberg (1997) offered a social cognitive model of self-regulated writing, with a focal point on how writers initiate and control the writing process, and which strategies may facilitate writing development. The authors define self-regulated writing as a complex system of interdependent processes interacting reciprocally, presenting it as more than an individual-differences construct. There is limited research, however, examining the role that contextual variables may play in what students do when writing (Graham \& Rijlaarsdam, 2016), including their role in students' strategic options to initiate and control writing tasks (Kaplan, Lichtinger, \& Gorodetsky, 2009).

The present study aims to extend knowledge on writing development by exploring contextual variations in students' use of different self-regulated strategies for school writing tasks. We designed this exploratory research to identify and compare environmental, behavioural, and personal strategies that students reported using, having the same official language of instruction-Portuguese - but operating in different educational contexts - Portugal and Brazil. A subsequent aim was to examine gender diversity in the reported use of the assessed strategies. Considering the apparent gender gap in text composing (see Gelati for a review, 2012), this research is needed to gain insights into the role that contextual variables play when examining gender differences in writing development.

\section{Social-Cognitive Perspective of Self-Regulated Writing}

Cognitive research developed during the 1980's has served as grounds for the current conception of writing as a process. Hayes and Flower's (1980) cognitive model of writing and Bereiter and Scardamalia's (1987) model explaining the differences between novice and expert writers in text production have been a major contribution to the current understanding of what writing is and how it is developed. While these cognitive models described writing as mainly an individual process of thinking and meaning transformation, others defended the importance that contextual variables may have in the writing process (Nystrand, 2006; Schultz \& Fecho, 2000). These perspectives are based on two main assumptions: a) writing is often a solitary cognitive act of producing meaning, framed in the individual writer's imagination, knowledge, and experiences (Berninger, 2012); b) writing is an act of communication between a writer and an audience within a larger linguistic and socio-cultural context (Nystrand, 2006). 
Taken together, these assumptions highlight the need to examine individual and context-specific variables that predict writing development, asserting the need to draw on a multidisciplinary theoretical framework to investigate self-regulated writing.

Zimmerman and Risemberg (1997) introduced a social cognitive model for writing, defining self-regulated writing as 'self-initiated thoughts, feelings, and actions that writers use to attain various literacy goals' (p.76). The authors present self-regulated writing as a complex system of interdependent processes that interact reciprocally. Grounded in Bandura's social cognitive theory (1986), they propose three major factors to explain how writers act to deliberately initiate and control their writing: environmental processes, said to reflect arrangements made by the writers to structure physical and social settings to optimize writing; behavioural processes, referring to writers' use of overt motoric performance strategies for writing; finally, personal processes, described as writers' regulation of personal (covert) cognitive beliefs and affective states associated with text composition. Describing self-regulation as more than a trait or ability one possesses, the authors suggest that these three major forms of self-regulation interact during writing through a cyclic feedback loop. In the process, writers self-monitor the effectiveness of specific self-regulatory strategies and self-react, selecting either to continue using their strategies or to change them if they are found to be ineffective. Proficient self-regulated writers use all three major processes of self-regulation concurrently (Zimmerman \& Risemberg, 1997).

\section{Using Self-Regulated Strategies for Writing}

Expressing and articulating complex ideas accurately in a number of different writing tasks, for different curriculum purposes, are requirements for the academic success of secondary school students. Thus, it becomes important to identify specific strategies that students use to self-regulate the writing process (Graham \& Harris, 2000). Research suggests skilled writers use a variety of strategies to regulate their actions: from general cognitive and metacognitive strategies, such as goal setting and planning, self-monitoring, organizing, self-evaluating and revising, to more contextual and behavioural strategies, such as environmental structuring, self-selecting models, and seeking social assistance (Harris, Santangelo, \& Graham, 2010).

Despite the few studies examining students' use of self-regulated strategies when having Portuguese as the language of instruction, research (Limpo \& Alves, 2013) found that middle-school students (Grades 7-9) use planning strategies for story and opinion essay writings, but hardly included revision strategies in the generation of both. Analysing students' discourse about writing, Barbeiro (2011) found that sixth-grade students used planning, revising, and editing strategies more frequently than younger students. Furthermore, participants 
did not consider adapting writing to a potential reader, confirming research reporting younger students' reliance on a knowledge-telling approach for text composing (Bereiter \& Scardamalia, 1987).

\section{The Role of Context}

There is extensive literature regarding the social and contextual influences underpinning writing development (see Prior, 2006 for a review). Schultz and Fecho's (2000) seminal review, for example, present writing development as a socially and contextually situated process. Miller and McCardle (2011) further stress the urgency of developing cross-cultural research to examine similarities and differences between writing across languages and socio-cultural settings. Nevertheless, cross-cultural empirical research on writing development and instruction is scarce (Graham \& Rijlaarsdam, 2016). Findings from one large international study examining the writing education of students in 16 countries made the case that cultural differences play a fundamental role in writing development and writing instruction (revised by Purves, 1992). On the one hand, conceptions of writing varied across countries, potentially affecting students' performance. As an example, Indonesian students generally approached writing tasks as personal narratives even when asked to write an argumentative text. On the other hand, using the same score to rate students' writing tasks across countries proved to be impossible, emphasising the difficulties in comparing writing performance across cultures and differences in teaching practices. Taken together, these findings argue for the idea that contextual and cultural differences may underpin students' writing development and, subsequently, students' strategic options to initiate and control their writings.

Discussing writing education across the world, Graham and Rijlaarsdam (2016) argue for the need to develop cross-cultural research examining what students do when performing different writing tasks. Developing self-regulated writing skills is inarguably important to promote academic success (Graham \& Harris, 2000; Malpique \& Veiga Simão, 2015; Nückles, Hübner, \& Renkl, 2009). However, research examining what students do to initiate and control school writing tasks across contexts is scarce. Kaplan, Lichtinger, and Gorodetsky (2009) tested the hypothesis that self-regulated writing may vary in different educational contexts depending on the particular task engagement and social goals shared in a learning environment. The authors compared 211 ninth-grade Israeli Jewish students enrolled in two different educational environments: traditional, in which content acquisition and evaluation were prioritised, and authentic, where learning was problem-based and students explored real life situations. After completing a writing assignment, participants were asked to answer a survey about their engagement in that specific writing task. Measuring students' achievement goal orientations, self-efficacy, and several self-regulated strategies for writing, their findings suggested that the contextual characteristics of learning environments might make use of certain strategies more relevant 
to students' pursuit of distinct mastery and performance goals. Considering self-regulated writing as a multidimensional construct, the authors suggested that 'writing may mean something different in different learning environments' (p. 64).

\section{Gender Diversity}

A pattern of female advantage in text composition has been found in national writing proficiency assessments across grades (Gelati, 2012). Findings indicate that girls are more able to produce texts with higher overall writing quality (Engelhand, Walker, Gordon, \& Gabrielson, 1994), produce more coherent and organised texts (Swanson \& Berninger, 1996), have faster handwriting (McCutchen, 1995), and are more motivated, presenting higher self-efficacy beliefs about successful outcomes (Graham, Berninger, \& Weihua, 2007; Pajares, Miller, \& Johnson, 1999).

Nevertheless, research findings have also questioned gender as a predictor of writing quality. When controlling for other variables such as compositional fluency (Berninger, Whitaker, Feng, Swanson \& Abbott, 1996), the results showed non-significant or mixed gender differences in text composition (Pajares, Miller, \& Johnson, 1999). Focusing on gender identity shaping and being shaped by different cultural and social practices, research findings suggest that boy's prefer to write about fiction and sports, avoiding the romance topics favoured by girls as a way to perform their masculine identity (Blake, 1995; Peterson, 2002). Hence, authors have argued for the need to examine cultural and contextual variables underpinning the apparent gender gap in writing (Jones, 2007; Peterson, 2002).

\section{The Present Study}

From different educational contexts, the authors share similar concerns regarding the writing difficulties of a growing number of school-aged children (Berninger, 2012; Myhill \& Fisher, 2010). In Portugal, data collected nationwide on secondary student academic achievement suggested writing difficulties across multiple subject areas (Malpique \& Veiga Simão, 2012; Sousa, Ferreira, Romão, Pereira, \& Lourenço, 2013). In Brazil, studies reported similar findings discussing writing problems across grade levels (Cunha \& Santos, 2006). In a recent study, Veiga Simão and colleagues (2016) found differences between Portuguese and Brazilian middle-school teachers' practices and perceptions about writing. The authors found that teachers rarely employed practices to promote students' self-regulated writing, such as developing prewriting activities or teaching proof reading strategies (Veiga Simão, Malpique, Frison, \& Marques, 2016). Taken together, these results help make the case that perceptions and practices for writing development and writing instruction may immerge in different educational and cultural contexts, substantiating the need to develop empirical research investigating Portuguese and Brazilian students' options to self-regulate their writing. 
The current research is part of a larger project aiming to evaluate the effectiveness of an intervention program to improve ninth-grade Portuguese students' writing achievement. Research investigating how students regulate the composing process when having Portuguese as the language of instruction is limited (Barbeiro, 2011; Limpo \& Alves, 2013). We designed this exploratory research to gain insights into the role that contextual and cultural variables play in students' use of different self-regulated strategies for writing. For cross-cultural comparisons, we followed Triandis's (1996) definition of culture as "shared elements that provide the standards for perceiving, believing, evaluating, communicating, and acting among those who share a language, a historic period and a geographic location" (p. 408).

The following research questions served our inquiry frame:

1. The first research question addressed in the present study was: do ninth-grade students from different cultural and educational contexts report using different strategies to initiate and control their school writing tasks? Despite the limited research investigating self-regulated writing from a contextual perspective, research previously reviewed here suggest that students use different strategies to initiate and control the writing process in different educational contexts (Kaplan, Lichtinger, \& Gorodetsky, 2009). Furthermore, research on writing instruction indicated statistically significant differences between Portuguese and Brazilian teachers' practices for teaching writing and perceptions about writing (Veiga Simão et al., 2016), including in the practices used to promote self-regulated writing. Thus, we anticipated differences between Portuguese and Brazilian students reported use of self-regulated strategies for writing. Because we chose a triadic measure to assess students' strategy use, a subsequent aim was to investigate whether such differences would tap environmental, behavioural, and/or personal strategies for writing. However, given the lack of cross-cultural studies examining these specific variations, we did not make any further predictions.

2. As noted earlier when reviewing research on gender differences in writing, there is a pattern of female advantages in several variables measuring writing performance and quality. Therefore, we asked: are there gender differences in students' use of self-regulated strategies for writing? We predicted differences favouring girls in the reported use of a considerable number of the examined self-regulated strategies. Nevertheless, given the exploratory nature of the current study and the lack of similar studies using a triadic measure to compare students' self-regulated strategy use for text composition, we could not anticipate in which of the three major processes of self-regulated writing (environmental, behavioural, and personal) such differences would occur. 
3. The final question addressed was: does gender intersect with cultural contexts in the process of initiating and controlling school writing talks? Besides investigating gender differences, a subsequent aim of the current study was to investigate single-sex differences in the reported use of different self-regulated strategies for writing. This option stemmed from the previous literature reviewed here (Jones, 2011) suggesting the importance of exploring single-sex cohorts to examine diversity within the categories of male and female. It is argued that investigating gender diversity may provide a more comprehensive view of writing in context, adding a more nuanced interpretation of the apparent gender gap in writing. Considering the lack of research on this, we did not make any predictions regarding this specific question.

\section{Method}

\section{Participants and Settings}

Students in transition to high school $\left(M_{\text {age }}=14.3\right.$ years, $S D=0.9$, age range 12 - 17) from five schools in Portugal and twelve schools in Brazil were used as participants for this study $(N=732)$. The Portuguese participants (Grade 9, $n=372, M_{\text {age }}=14.5$ years, $S D=0.8$, age range $13-17 ; 165$ male and 207 female) came from mainstream state schools, part of four public clusters in the Lisbon metropolitan area. Following a provision policy grounded in a social model, typical classes include students with different educational needs, and thus the writing achievement of individual students varies considerably. Writing is systematically used as a learning and assessment tool across all subject areas. In the last two decades, and following the shift from product to process writing, statutory frameworks offer guidelines related to the teaching of writing in schools. However, middle school (year 7 to year 9) and secondary school (year 10 to year 12) curricular guidance for writing is restricted to Portuguese and Second Language learning classes. Students are tested frequently and receive numeric grades on their writing assignments throughout the school year, and on national exams (end of year 4, 6, 9, and 12). The population that the schools serve is predominantly white, urban, and middle class.

The Brazilian participants (Grade 9, $n=360, M_{\text {age }}=14.2$ years, $S D=1.0$, age range 12-17; 158 male and 202 female) were a similar cohort of students from mainstream state urban schools, part of four public clusters in the South Region of Brazil. Since 2006, the length of compulsory education was nine years, starting from the age of six. From the late 90 's, national curriculum guidelines set standards for the teaching of writing following a process-oriented approach. Achievement goals for writing are restricted to Portuguese language classes, with guidelines on how to teach planning, translating, and revising. National standardised tests are administered to students in Grades 5, 9, and 12. The population of the schools involved is predominantly white, urban, and middle class. 
We used the schools' average grades in language arts national exams (year 9 in both educational systems) to compare overall achievement in literacy and writing. The general achievement scores of the Portuguese schools involved was $M=2.96(S D=.20)$, with results ranging from 2.7 to 3.2. The average score of the Brazilian schools involved was $M=2.99(S D=.28)$, ranging from 2.8 to 3.4. The average scores for the two countries did not differ statistically, $p=.67$.

\section{Procedure}

A questionnaire was administered to whole classes by the first researcher to students in Portuguese schools and by the research colleague from the partner university to students in Brazilian schools. A team of linguists checked and reviewed the items to control for EP and BP variations. We collected data at the beginning of the school year in both countries (September/October in Portugal, and February/March in Brazil), and we obtained parents and carers' consent for that purpose. Researchers explained the project to the heads of schools and teachers and informed students, verbally and in written form, that they were participating in a survey about the strategies they use in school writing tasks. Before completing the questionnaire, researchers read and explained instructions. Students were asked to report the frequency with which they used the strategies described when facing writing tasks in different subjects across the curriculum. Mean completion time was 15 minutes.

\section{Instrument}

Given the limited number of instruments measuring the use of self-regulated strategies for writing (Kanlapan \& Velasco, 2009; Kaplan, Lichtinger, \& Gorodetsky, 2009) and their lack in the context of writing in Portuguese, we used a self-report instrument designed and validated by Malpique and Veiga Simão (2015) to assess twelve self-regulated strategies for writing. Following Zimmerman and Risemberg's (1997) social cognitive model for writing, the questionnaire comprised items grouped on 10 proposed subscales measuring the three major categories of self-regulatory influence. The first major category - environmental processes - included environmental structuring and help-seeking strategies; the second - behavioural processes - included self-monitoring, self-consequating, and self-verbalising strategies; the last category - personal processes - included strategies for time planning, self-evaluating, recalling/creating mental images, and four primarily cognitive strategies, namely planning, revising, organising, and reader's awareness. The instrument included 34 items assessing 12 self-regulated strategies for writing (see Appendix A for examples of items included in each scale). Response options followed a five point Likert-scale from $1=$ Very Rarely to $5=$ Very Frequently.

Table 1 presents the descriptive statistics and the reliability of the variables in the study. Analyses showed reasonably good reliability indices for each of the subscales, especially for Personal Processes, $\alpha=.88$. Except for Behavioural 
Processes, with only one measure, $\alpha=.61$, all measures had internal consistencies (Cronbach's alphas) at .65 or above. As the purpose of this study was to identify more generally the students' reported use of self-regulated strategies for writing, and if cultural context influences may make certain strategies more or less relevant for students, we decided to include the aforementioned measure in the analyses. Conclusions concerning the findings related to that strategy should be taken with caution.

Table 1. Descriptive statistics of variables in the study

\begin{tabular}{lccc}
\hline Variable & No. items & $\boldsymbol{M}(\boldsymbol{S D})$ & $\boldsymbol{\alpha}$ \\
\hline Environmental Processes & & & .68 \\
Environmental structuring & 3 & $3.46(1.14)$ & .81 \\
Help-seeking & 2 & $2.43(1.16)$ & .69 \\
Behavioural Processes & & & .62 \\
Self-monitoring & 3 & $3.16(1.42)$ & .61 \\
Self-consequating & 3 & $3.25(1.02)$ & .69 \\
Self-verbalising & 2 & $3.23(0.91)$ & .65 \\
Personal Processes & & & .88 \\
Time planning & 3 & $2.840 .91)$ & .67 \\
Self-evaluating & 3 & $3.83(1.01)$ & .65 \\
Planning & 5 & $3.53(0.76)$ & .67 \\
Revising & 2 & $3.73(1.06)$ & .74 \\
Organising & 2 & $2.83(1.13)$ & .70 \\
Reader's awareness & 3 & $2.64(1.15)$ & .79 \\
Recalling/creating mental images & 3 & $3.52(1.05)$ & .75 \\
\hline
\end{tabular}

In most cross-cultural studies of SRL, not much attention has been given to multi-group invariance analysis to ensure cross-cultural validity of the developed instrument (McInerney, 2011), which may substantiate meaningful comparisons between cultural groups. For that purpose, multi-group invariance tests were performed, with results suggesting that the 34 item measures of the questionnaire may be robust across the examined cultures, $\chi^{2}(1042)=1712.176$, $p<.05, \chi_{d f}^{2}=1.643$, comparative fit index $=.90$, root mean square error of approximation $=.030$.

\section{Results}

To investigate the relationship between self-regulated strategies for writing, cultural groups and gender, we computed a two-way multivariate analysis of variance (MANOVA) - 2 (group: Portuguese and Brazilian) x 2 (group: Male and Female) - with the 12 strategies serving as dependent variables. The results 
indicated a significant multivariate main effect for country, $F(12,717)=12.81$, $p=.000$, Wilk's lambda $=.82, \eta_{p}^{2}=.17$, and for gender, $F(12,717)=7.62$, $p=.000$, Wilk's lambda $=.89, \eta_{p}{ }^{2}=.11$. The interaction effect was not statistically significant.

Given the significance of the main effect for cultural groups, we examined univariate main effects to investigate differences between countries in the reported use of the 12 strategies. We also tested the 12 a priori hypotheses using Bonferroni-adjusted alpha levels of .002 per test $(.05 / 24)$, to control for Type I error rate. Table 2 shows mean strategy scores for cultural groups. The results indicated that the two groups differed significantly in the reported use of six of the 12 self-regulated strategies. Portuguese students scored significantly higher on self-monitoring, $F(1,728)=9.639, p=.002, d=0.22$; time planning, $F(1,728)=52.903, p=.000, d=0.53$; planning, $F(1,728)=15.102, p=.000$, $d=0.25$; organising, $F(1,728)=84.923, p=.000, d=0.68$; reader's awareness, $F(1,728)=9.138, p=.002, d=0.24$; and recalling/creating mental images, $F(1,728)=36.296, p=.000, d=0.44$.

Table 2. Means (and standard deviations) of strategy scores for country and gender

Strategy score

\begin{tabular}{cccc}
\hline \multicolumn{2}{c}{ Country } & \multicolumn{2}{c}{ Gender } \\
\hline Portuguese & Brazilian & Male & Female \\
$(n=\mathbf{3 7 2})$ & $(n=\mathbf{3 6 0})$ & $(n=\mathbf{3 2 3})$ & $(n=409)$ \\
\hline
\end{tabular}

\section{Environmental Processes}

Environmental structuring

$3.55(1.05)$

$3.38(1.23)$

$3.32(1.20)$

$3.58(1.08)$

Help-seeking

2.40 (1.11)

2.47 (1.22)

$2.39(1.20)$

$2.47(1.14)$

\section{Behavioural Processes}

\begin{tabular}{lcccc} 
Self-monitoring & $3.32(1.40)^{\mathrm{a}}$ & $3.00(1.43)^{\mathrm{a}}$ & $3.05(1.37)$ & $3.26(1.46)$ \\
Self-consequating & $3.29(0.99)$ & $3.22(1.06)$ & $3.33(1.00)$ & $3.20(1.04)$ \\
Self-verbalising & $3.44(0.77)$ & $3.36(0.97)$ & $3.31(0.89)$ & $3.47(0.87)$ \\
Personal Processes & & & & \\
Time planning & $3.07(0.88)^{\mathrm{a}}$ & $2.60(0.89)^{\mathrm{a}}$ & $2.70(0.91)^{\mathrm{b}}$ & $2.96(0.90)^{\mathrm{b}}$ \\
Self-evaluating & $3.84(0.85)^{\mathrm{b}}$ & $3.83(1.16)$ & $3.64(1.13)^{\mathrm{b}}$ & $3.99(0.88)^{\mathrm{b}}$ \\
Planning & $3.62(0.65)^{\mathrm{a}}$ & $3.43(0.85)^{\mathrm{a}}$ & $3.35(0.76)^{\mathrm{b}}$ & $3.67(0.73)^{\mathrm{b}}$ \\
Revising & $3.72(0.96)^{\mathrm{b}}$ & $3.76(1.17)$ & $3.43(1.14)^{\mathrm{b}}$ & $3.98(0.93)^{\mathrm{b}}$ \\
Organising & $3.19(1.02)^{\mathrm{a}}$ & $2.46(1.12)^{\mathrm{a}}$ & $2.68(1.07)^{\mathrm{b}}$ & $2.96(1.16)^{\mathrm{b}}$ \\
Reader's awareness & $2.77(1.11)^{\mathrm{a}}$ & $2.50(1.17)^{\mathrm{a}}$ & $2.49(1.11)^{\mathrm{b}}$ & $2.76(1.16)^{\mathrm{b}}$ \\
Recalling/creating images & $3.75(0.96)^{\mathrm{a}}$ & $3.30(1.09)^{\mathrm{a}}$ & $3.23(1.07)^{\mathrm{b}}$ & $3.75(0.98)^{\mathrm{b}}$ \\
\hline
\end{tabular}

Note. Coefficients in the same row that share a superscript are significantly different from each other. Coefficients without superscript letters are not significantly different from the other coefficients. 
These results indicate that except for self-monitoring strategies, all significant differences tapped strategies under the personal processes scale. Both groups of students stated using self-evaluating, planning, and revising strategies more frequently. Mean scores for help-seeking and readers' awareness strategies were low for both groups, and time planning and organising got low scores for the Brazilian students.

Given the significance of the main effect for gender, we examined univariate main effects and tested the 12 a priori hypotheses using Bonferroni-adjusted alpha levels of .002 per test (.05/24). We found significant statistical differences between the two groups in eight out of the 12 strategies, namely one strategy tapping behavioural processes, and under all seven strategies tapping personal processes, overall favouring female students. Effect size values for all the differences found between gender groups were small, $d<0.20$ (see Table 2).

We computed pairwise comparisons to examine differences within gender groups - all-male students (Portuguese and Brazilian male) and all-female students (Portuguese and Brazilian female) - on the 12 self-regulated strategies under assessment. Table 3 shows mean strategy scores for the all-male and all-female groups. We used Bonferroni-adjusted alpha levels of .001 per test $(.05 / 48)$ to control the overall Type I error rate. We found statistically significant differences within male groups in five strategies tapping behavioural and personal processes. Overall, Portuguese male students scored significantly higher on self-monitoring, $F(1,728)=5.851, p=.001, d=0.28$; time planning, $F(1,728)=23.733$, $p=.000, d=0.42$; planning, $F(1,728)=12.487, p=.000, d=0.36$; organising, $F(1,728)=37.649, p=.000, d=0.73$; and recalling/creating mental images, $F(1,321)=11.290, p=.000, d=0.28$. The groups stated using self-evaluating, environmental structuring, planning, and revising strategies more frequently. Help-seeking, readers' awareness, and time planning strategies were the least consistently reported strategies. Brazilian male adolescents also reported using self-monitoring and organising strategies less frequently.

All-female comparisons revealed significant differences in four strategies tapping personal processes. Overall, Portuguese female students scored significantly higher time planning, $F(1,728)=29.895, p=.000, d=0.54$; organising, $F(1,728)=28.559, p=.000, d=0.66$; reader's awareness, $F(1,728)=10.751, p=.001, d=0.32$; and recalling/creating mental images, $F(1,728)=25.803, p=.000, d=0.52$. Within female groups, self-evaluating, planning, and revising were the three most consistently referred strategies. Similar to the results comparing all-male groups, female groups reported using help-seeking and reader's awareness strategies less frequently. 
Table 3. Means (and standard deviations) of strategy scores for all-male and all-female groups

\begin{tabular}{lcccc}
\hline & \multicolumn{4}{c}{ Strategy score } \\
\cline { 2 - 5 } & \multicolumn{2}{c}{ All-Male Groups } & All-Female Groups \\
\cline { 2 - 5 } & $\begin{array}{c}\text { Portuguese } \\
(n=\mathbf{1 6 5})\end{array}$ & $\begin{array}{c}\text { Brazilian } \\
(n=\mathbf{1 5 8})\end{array}$ & $\begin{array}{c}\text { Portuguese } \\
(n=\mathbf{2 0 7})\end{array}$ & $\begin{array}{c}\text { Brazilian } \\
(n=\mathbf{2 0 2})\end{array}$ \\
\hline Environmental Processes & & & & \\
Environmental structuring & $3.38(1.10)$ & $3.26(1.30)$ & $3.68(0.99)$ & $3.47(1.16)$ \\
Help-seeking & $2.43(1.18)$ & $2.35(1.22)$ & $2.38(1.05)$ & $2.57(1.21)$ \\
Behavioural Processes & & & & \\
Self-monitoring & $3.23(1.40)^{\mathrm{a}}$ & $2.85(1.32)^{\mathrm{a}}$ & $3.39(1.40)$ & $3.12(1.51)$ \\
Self-consequating & $3.43(0.99)$ & $3.22(0.99)$ & $3.17(0.98)$ & $3.22(1.11)$ \\
Self-verbalising & $3.33(0.73)$ & $3.29(1.02)$ & $3.52(0.80)$ & $3.42(0.93)$ \\
Personal Processes & & & & \\
Time planning & $2.93(0.85)^{\mathrm{a}}$ & $2.45(0.90)^{\mathrm{a}}$ & $3.19(0.88)^{\mathrm{b}}$ & $2.72(0.86)^{\mathrm{b}}$ \\
Self-evaluating & $3.62(0.85)$ & $3.66(1.38)$ & $4.02(0.81)$ & $3.95(0.95)$ \\
Planning & $3.48(0.65)^{\mathrm{a}}$ & $3.21(0.83)^{\mathrm{a}}$ & $3.74(0.62)$ & $3.60(0.83)$ \\
Revising & $3.42(1.00)$ & $3.44(1.27)$ & $3.96(0.85)$ & $4.01(1.01)$ \\
Organising & $3.03(0.99)^{\mathrm{a}}$ & $2.30(1.02)^{\mathrm{a}}$ & $3.32(1.02)^{\mathrm{b}}$ & $2.59(1.18)^{\mathrm{b}}$ \\
Reader's awareness & $2.56(1.07)$ & $2.42(1.16)$ & $2.94(1.12)^{\mathrm{b}}$ & $2.57(1.18)^{\mathrm{b}}$ \\
Recalling/creating images & $3.43(0.97)^{\mathrm{a}}$ & $3.04(1.12)^{\mathrm{a}}$ & $4.00(0.87)^{\mathrm{b}}$ & $3.50(1.03)^{\mathrm{b}}$ \\
\hline
\end{tabular}

Note. Coefficients in the same row that share a superscript are significantly different from each other. Coefficients without superscript letters are not significantly different from the other coefficients.

\section{Discussion}

In the present exploratory study, we investigated ninth-grade students' responses regarding how they initiate and control their school writing tasks in distinct cultural and educational contexts. We also addressed between and within gender differences among students' responses. Research questions and interpretation of the results are presented below.

\section{Do ninth-grade students from different cultural and educational contexts report using different strategies to initiate and control their school writing tasks?}

We found statistically significant differences between Portuguese and Brazilian students on six out of the 12 assessed self-regulated strategies for writing. These results support research on the role context variables may play in students' use of strategies for text organisation (Kaplan, Lichtinger, \& Gorodetsky, 2009). We also found meaningful differences between Portuguese and Brazilian students on strategies used to plan their school writings. These results are in line 
with research suggesting that older Portuguese students use planning strategies for text composition (Barbeiro, 2011; Limpo \& Alves, 2013). Interestingly, in the current study $58 \%$ of the students stated seldom creating a written plan before writing. Although not all planning occurs in paper, the infrequent construction of a written plan might be associated with the difficulties students seem to have with managing time for writing (Graham \& Harris, 2000), which was one of the strategies reported less frequently by both groups. Research comparing teaching practices and perceptions about writing in middle-schools found that $75 \%$ of Portuguese and $54 \%$ of Brazilian teachers included explicit methods to teach self-regulated writing very infrequently (Veiga Simão et al., 2016). Moreover, while both groups of teachers viewed teaching writing as a shared responsibility, Brazilian teachers perceived this idea to be more important. On the other hand, Portuguese teachers viewed writing as more important for students' academic and professional success. Taken together, these results highlight the role of context and culture in self-regulated writing, suggesting that a more sophisticated question than 'Do students plan?' might be to ask 'When, where, why, and how do students plan?'.

In the present study, cross-cultural comparisons indicated variations in the use of the examined self-regulated strategies, but they simultaneously draw attention to several marked similarities. Findings from the present study suggest that ninth-grade students are overall reluctant to seek assistance for writing and to use strategies to fit writing to potential readers. These last results may support cognitive developmental theories of learning to manage the composition process throughout the lifespan (Bereiter \& Scardamalia, 1987; Kellogg, 2008). According to Kellogg (2008), fitting writing to a possible reader is a particularly complex task, especially during the earlier stages of writing development. The author suggested that by the age of 14 - our participants' mean age - to 16 years, and having spent about ten years of learning how to manage the composing process, adolescents enter an intermediate stage of their writing development of knowledge-transforming. At this stage, the writer might still have too unstable reader representations to be kept in working memory, which imposes serious difficulties in the coordination of author, text, and reader representations while composing.

Current results may also reflect differences between educational systems. Indeed, despite the similar policies for teaching writing in Portugal and in Brazil, practices for teaching writing may differ and teachers may uphold different perceptions about writing and writing instruction (Veiga Simão et al., 2016), which in turn may affect students' development of self-regulated strategies for writing. Considering that learning to write is 'acquired through culturally specific, formal and informal systems of pedagogy' (Luke, 1988, p.17), differences between Portuguese and Brazilian students' options to initiate and control their writings reinforce the idea that self-regulated writing is a culturally and contextually bounded process. 


\section{Are there gender differences in the reported use of self-regulated strategies for writing?}

Our findings provide evidence for differences between gender groups in the reported use of several self-regulated strategies for writing. For these comparisons, we divided our sample into two groups of male and female participants, with a data set stratified by age, gender, and country. Although the results seemed to confirm expectations regarding girls' more frequent use of these strategies than boys, small effect sizes were found supporting differences between genders. Interestingly, the findings also seemed to suggest that gender differences did not occur in strategies tapping environmental or behavioural processes of self-regulated writing. Female students seemed to report using all seven personal strategies to initiate and control their school writing tasks more consistently than male students. Research has provided support for the association between specific characteristics of students and the tendency to report accurately, including students' gender (Pajares, 2002). Examining gender differences in the use of self-regulated learning strategies, researchers typically report results favouring female students (Peterson, 2002; Zimmerman \& Martinez-Pons, 1988). However, gender differences may be the result of other factors, such as the stereotypical beliefs students hold about gender, gender tendencies to respond with a distinct frame of mind, and sociocultural and/or educational influences (for a review, see Pajares, 2002).

\section{Does gender intersect with cultural contexts in the process of initiating and controlling school writing talks?}

Over the last few years, research on gender and educational achievement in general (Hadjar, Krolak-Schwerdt, Priem, \& Glock, 2014; Lahelma, 2014), and on gender and writing in particular (Jones, 2007, 2011), has undergone a paradigm shift by emphasising the need to consider gender as a complex and diverse category, rather than a fixed individual variable. A contribution of the current study results from the option of examining gender diversity through a cultural lens. For that, this study explored single-sex differences in the examined self-regulated strategies for writing.

Our results reinforce the idea that cultural contexts may play a role in how students initiate and control their school writing tasks. Restricting data analysis to between gender group differences could have led to misleading interpretations concerning the use of two strategies. First, despite gender differences apparently favouring female adolescents in the use of self-monitoring strategies, our results provided evidence of male students' positive response to the use of these strategies (mean score greater than 3.0). Nevertheless, all-male group comparisons allowed for a different interpretation of these findings. Significant differences between Portuguese and Brazilian male groups showed that the last group used self-monitoring strategies less frequently (mean score below 3.0). Second, 
another possible misleading interpretation of results concerns time-planning strategies, which were negative for male and female groups despite the significant differences favouring females. When comparing all-female responses, our results support the idea that Portuguese females, unlike their counterparts, might use strategies to manage time for writing with some consistency. The significant differences found within groups seem to provide initial evidence of how gender may intersect with context and culture in self-regulated writing, reinforcing the complexity involved in assessing writing development and self-regulation in context.

\section{Assessing self-regulated strategies for writing from a social cognitive perspective}

These results strongly indicate the need for further discussion of the apparently tangled process of assessing the use of self-regulated strategies for writing, especially when taking a social cognitive perspective. Regarding the three major processes of self-regulated writing, predictably similar to results from cross-cultural differences, differences within male and female groups were found on strategies measuring behavioural processes - self-monitoring (within male only) -, and personal processes - time planning, organising, planning (within male only), reader's awareness (within female only), and recalling/creating mental images for text composition. We found no differences within genders in strategies tapping environmental processes.

These findings may be accounted for by at least three reasons. The most straightforward reason might be related to the number of strategies included in each process, which is confined to two strategies assessing environmental processes. A second possibility is that the self-report instrument developed for this study, which is limited to a specific moment in time of the students' report, cannot provide evidence of the triadic reciprocal interaction involved in the process of self-regulated writing. Attempts to understand which variables cause a continuous or a discontinuous use of specific writing strategies may require more complex measures, especially when considering the enactive feedback loop that triggers the interaction between the processes (Zimmerman \& Risemberg, 1997). Another possibility is that some strategies may vary less. Depending either on historical and culturally accepted conventions (such as finding a quiet room to write) or learning development stages (such as adolescents' willingness to seek help), environmental strategies might be a more stable category in the process of self-regulated writing. However, personal processes, the category in which most significant differences were found, may be a less stable category and, thus, more vulnerable to contextual and cultural variables. 


\section{Limitations and Future Research}

The present study has several limitations that should be considered. First, interpretations of the current findings are a result of an exploratory study aiming to gain insights into the role that context and culture may play in students' strategic decision making to initiate and control school writing tasks. These interpretations were limited to students reported use of the strategies. Thus, conclusions regarding their actual use in either Portuguese or Brazilian contexts cannot be made. Surveys and inventories have been one common method for assessing self-regulation and strategy use in different domains (Meijer et al., 2013; Wolters, Benzon, \& Arroyo-Giner, 2011). These instruments allow researchers to collect a large amount of data about particular constructs with lower costs regarding expenses and time. More importantly, self-report instruments may be a key advantage when considering a construct like self-regulated writing from a triadic social contextual perspective, like that of the current research, which incorporates a large number of different types of strategies. Nonetheless, findings from the current study must be supported by subsequent research, which may use the self-report questionnaire here developed for initial measurement of students' use of self-regulated strategies for writing in a particular educational context, along with more complex assessment measures such as structured interviews and observation of writing performance. Furthermore, researchers should investigate whether these findings can be generalised to students with different characteristics and with different languages of instruction. Secondly, several factors may have underpinned the present findings, including differences in school sizes, demographic, and socioeconomic differences (to name a few). These variables, which were not assessed in the current study, should be included in future research aiming to substantiate cross-cultural comparisons and reinforce the validity of examining writing in context. Finally, this research did not investigate students' use of self-regulated strategies for writing in relation to their writing achievement. Previous research with American students examining secondary school students' (year 7 to year 12) use of self-regulated strategies for writing has found that high-achieving writers make greater use of certain strategies. In particular, these students showed a greater reliance on planning, revising, organising, and help-seeking strategies (Harris \& Graham, 2009; Kellogg, 2008). Examining self-regulated writing from a contextual perspective, authors have found that Israeli Jewish high-achieving ninth-grade writers made greater use of those same strategies, except for the last, reporting less reliance on social sources of assistance (Kaplan, Lichtinger, \& Gorodetsky, 2009). Further research is needed to address the question of whether the strategies used by Portuguese and/or Brazilian students contribute to their writing achievement. 


\section{Conclusions and Implications for Theory and Practice}

The findings of the current study provide initial support for the idea that initiating and controlling writing is a contextually and culturally bounded process. This implies that students may vary in the type of strategies they use to self-regulate their writing (Graham \& Harris, 2000), that such variations may emerge among students from different schools within the same educational contexts (Kaplan, Lichtinger, \& Gorodetsky, 2009), amongst students with differing cultural backgrounds within the same language of instruction, and that strategies may vary between and within gender groups.

Findings from the current study also support theoretical and methodological claims concerning the need to represent gender diversity in writing research (Jones, 2007, 2011). Investigating how gender intersects with cultural contexts seems to question more recurrent options of representing male and female differences as two homogeneous variables. Results from this study highlight the illusive quality of such a stand, stressing the need to look beyond first interpretations based on gender differences.

Current findings, however, must be supported by subsequent research attempting to provide a more comprehensive analysis of cross-cultural variations in self-regulated writing. Researchers aiming to confirm these findings should consider contextual differences in the underlying writing education, including teaching practices. In many countries research on writing instruction is particularly scarce, and teachers' instructional practices and perceptions about writing differ across educational contexts and cultures (Graham \& Rijlaarsdam, 2016; Veiga Simão et al., 2016). Future research is clearly needed to examine classroom-level predictors of self-regulated writing, including writing instruction variables but also overall classroom quality, such as classroom organisation and instructional support. Expanding our knowledge on individual and classroom variables that may explain the use of different self-regulated strategies for text composing would make a significant contribution to understanding the multidimensional nature of writing and, in turn, substantiate teacher teaching programs and governmental policies to foster students' writing development.

\section{References}

Alexander, P., Graham, S., \& Harris, K.R. (1998). A perspective on strategy research: Progress and prospects. Educational Psychology Review, 10, 129-154. doi: https://doi.org/10.1023/A:1022185502996

Bandura, A. (1986). Social foundations of thought and action: A social cognitive theory. Englewood Cliffs, NJ: Prentice-Hall.

Barbeiro, L.F. (2011). What happens when I write? Pupil's writing about writing. Reading and Writing, 24, 813-834. doi: http://dx.doi. org/10.1007\%2Fs11145-010-9226-2 
Bereiter, C., \& Scardamalia, M. (1987). The psychology of written composition. Hillsdale, NJ: Lawrence Erlbaum Associates.

Berninger, V.W. (Ed.) (2012). Past, present, and future contributions of cognitive writing research to cognitive psychology. New York, NY: Psychology Press.

Berninger, V. W., Whitaker, D., Feng, Y., Swanson, H. L., \& Abbott, R. D. (1996). Assessment of planning, translating, and revising in junior high writers. Journal of School Psychology, 34, 23-52. doi: http://dx.doi. org/10.1016\%2F0022-4405\%2895\%2900024-0

Blake, B. E. (1995). Broken silences: Writing and the construction of 'cultural texts' by urban, preadolescent girls. Journal of Educational Thought, 29, 165-180. Retrieved from http://www.jstor.org/stable/23767675

Cunha, N. B., \& Santos, A. (2006). Relação entre a compreensão de leitura e a produção escrita em universitários [The relation between college students' reading comprehension and writing]. Psicologia: Reflexão e Crítica, 19, 237-245. doi: http://dx.doi.org/10.1590\%2FS0102-79722006000200009

Engelhand, G. J., Walker, E. V. S., Gordon, B., \& Gabrielson, S. (1994). Writing tasks and gender: Influences on writing quality of black and white students. The Journal of Educational Research, 87, 197-209. doi: http://dx.doi.org/10 .1080/00220671.1994.9941244

Gelati, C. (2012). Female superiority and gender similarity effects and interest factors in writing. In V.W. Berninger (Ed.), Past, present, and future contributions of cognitive writing research to cognitive psychology (pp. 153-174). New York, NY: Psychology Press.

Graham, S., Berninger, V., \& Weihua, F. (2007). The structural relationship between writing attitude and writing achievement in first and third grade students. Contemporary Educational Psychology, 32, 516-536. http://dx.doi. org/10.1016\%2Fj.cedpsych.2007.01.002

Graham, S., \& Harris, K. R. (2000). The role of self-regulation and transcription skills in writing and writing development. Educational Psychologist, 35, 3-12. doi: http://dx.doi.org/10.1207\%2FS15326985EP3501_2

Graham, S., MacArthur, C. A., \& Fitzgerald, J. (Eds.) (2013). Best practices in writing instruction. New York, NY: Guilford Press.

Graham, S., \& Rijlaarsdam, G. (2016). Writing education around the globe: Introduction and call for a new global analysis. Reading and Writing: An Interdisciplinary Journal, 26, 781-792. doi: 10.1007/s11145-016-9640-1

Hadjar, A., Krolak-Schwerdt, S., Priem, K., \& Glock, S. (2014). Gender and educational achievement. Educational Research, 56, 117-125. doi: http:// dx.doi.org/10.1080/00131881.2014.898908

Hayes, J. R., \& Flower, L. (1980). Identifying the organization of writing processes. In L. W. Gregg \& E. R. Steinberg (Eds.), Cognitive processes in writing (pp. 3-29). Hillsdale, NJ: Erlbaum. 
Harris, K. R., \& Graham, S. (2009). Self-regulated strategy development in writing: Premises, evolution, and the future. British Journal of Educational Psychology Monograph Series II, 1, 113-135. doi: http://dx.doi. org/10.1348\%2F978185409X422542

Harris, K. R., Santangelo, T., \& Graham, S. (2010). Metacognition and strategies instruction in writing. In H. S. Waters \& W. Schneider (Eds.), Metacognition, strategy use \& instruction (pp. 226-256). New York, NY: Guilford Press.

Jones, S. (2007). Composing in the style of Mozart: An exploration of the struggling boy writer comparing the composing processes and strategies of boys and girls. English Teaching: Practice and Critique, 6, 97-112.

Jones, S. (2011). Mapping the landscape: Gender and the writing classroom. Journal of Writing Research, 3, 161-179. Retrieved from http://hdl.handle. net $/ 10036 / 3508$

Kanlapan, M. T. C. E, \& Velasco, J. C. (2009). Constructing a self-regulation scale contextualized in writing. TESOL Journal, 1, 79-94. Retrieved from http://tesol-international-journal.com/wp-content/uploads/2013/11/A6V1_ TESOL[1].pdf

Kaplan, A., Lichtinger, E., \& Gorodetsky, M. (2009). Achievement goal orientations and self-regulation in writing: An integrative perspective. Journal of Educational Psychology, 101, 51-69. doi: http://dx.doi.org/10.1037/ a0013200.

Kellogg, R. T. (2008). Training writing skills: A cognitive developmental perspective. Journal of Writing Research, 1, 1-26. Retrieved from http:// www.jowr.org/articles/vol1_1/JoWR_2008_vol1_nr1_Kellogg.pdf

Lahelma, E. (2014). Troubling discourses on gender and education. Educational Research, 56, 171-183. doi: http://dx.doi.org/10.1080/00131881.2014.8989 13

Limpo, T., \& Alves, R. A. (2013). Modeling writing development: Contribution of transcription and self-regulation to Portuguese students' text generation quality. Journal of Educational Psychology, 105, 401-413. doi: http://dx.doi. org/10.1037/a0031391.

Luke, A. (1988). Literacy, textbooks and ideology. London: Falmer Press.

Malpique, A., \& Veiga Simão, A. M. V. (2012). Cinderela e o sapato de cristal: Ensinando estratégias de autorregulação para a composição escrita [Cinderella's crystal slipper: Teaching self-regulated strategies for writing]. In A. M. V. Veiga Simão, L. M. B. Frison \& M. H. M. B. Abrahão, Autorregulação da aprendizagem e narrativas autobiográficas: Epistemologia e práticas (pp. 155-178). Porto Alegre: EDIPUCRS.

Malpique, A., \& Veiga Simão, A.M. (2015). Assessing self-regulated strategies for school writing: Cross-cultural validation of a triadic measure. Journal of Psychoeducational Assessment, 33, 141-153. doi: 10.1177/0734282914547873 
Meijer, J., Sleegers, P., Elshout-Mohr, M., Daalen-Kapteijns, M., Meeus, W., \& Tempelaar, D. (2013). The development of a questionnaire on metacognition for students in higher education. Educational Research, 55, 31-52. doi: http:// dx.doi.org/10.1080/00131881.2013.767024

Myhill, D., \& Fisher, R. (2010). Editorial: Writing development: Cognitive, sociocultural, linguistic perspectives. Journal of Research in Reading, 33, 1-3. doi: http://dx.doi.org/10.1111/j.1467-9817.2009.01428.x

McCutchen, D. (1995). Cognitive processes in children's writing: Developmental and individual differences. Issues in Education, 1, 123-160.

McInerney, D. M. (2011). Culture and self-regulation in educational contexts; assessing the relationship of cultural group to self-regulation. In B. J. Zimmerman \& D. J. Schunk (Eds.), Handbook of self-regulation of learning and performance (pp. 442-464). New York, NY: Routledge.

Miller, B., \& McCardle, P. (2011). Reflections on the need for continued research on writing. Reading and Writing, 24, 121-132. doi: http://dx.doi. org/10.1007\%2Fs11145-010-9267-6

Nystrand, M. (2006). The social and historical context for writing research. In C. A. MacArthur, S. Graham \& J. Fitzgerald (Eds.), Handbook of writing research (pp. 11-27). New York, NY: Guilford Press.

Nückles, M., Hübner, S., \& Renkl, A. (2009). Enhancing self-regulated learning by writing learning protocols. Learning and Instruction, 19, 259-271. doi: http://dx.doi.org/10.1016/j.learninstruc.2008.05.002

Pajares, F. (2002). Gender and perceived self-efficacy in self-regulated learning. Theory Into Practice, 41, 116-125. doi: http://dx.doi. org/10.1207\%2Fs15430421tip4102_8.

Pajares, F., Miller, D. M., \& Johnson, M. J. (1999). Gender differences in writing self-beliefs of elementary school students. Journal of Educational Psychology, 91, 50-61. doi: http://dx.doi.org/10.1037\%2F\%2F0022-0663.91.1.50

Peterson, S. (2002). Gender meanings in grade eight student's talk about classroom writing. Gender and Education, 14, 351-366. doi: http://dx.doi. org/10.1080/0954025022000020081a

Prior, P. (2006). A sociocultural theory of writing. . In C. A. MacArthur, S. Graham \& J. Fitzgerald (Eds.), Handbook of writing research (pp. 54-66). New York, NY: Guilford Press.

Purves, A. C. (1992). Reflections on research and assessment in written composition. Research in the Teaching of English, 26, 108-122.

Schultz, K., \& Fecho, B. (2000). Society's child: Social context and writing development. Educational Psychologist, 35, 51-62. doi: http://dx.doi. org/10.1207\%2FS15326985EP3501_6

Sousa, D. H., Ferreira, M. A., Romão, R. B., Pereira, S., \& Lourenço, V. (2013). Projetos testes intermédios: Relatório 2012 [Mid-term evaluation project: 2012 report] Lisboa: GAVE. 
Swanson, H. L., \& Berninger, V. W. (1996). Individual differences in children's working memory and writing skills. Journal of Experimental Child Psychology, 63, 358-385. doi: http://dx.doi.org/10.1006\%2Fjecp.1996.0054

Triandis, H. C. (1996). The psychological measurement of cultural syndromes. American Psychologist, 51, 407. doi: http://dx.doi.org/10.1037/0003066X.51.4.407

Veiga Simão, A. M., Malpique, A., Frison, L. M. B, Marques, A. (2016). Teaching writing to middle school students in Portugal and in Brazil: An exploratory study. Reading and Writing: An Interdisciplinary Journal, 2, 955-979. doi: 10.1007/s11145-015-9606-8

Weinstein, C.E., Husman, J., \& Dierking, D.R. (2000). Self-regulation interventions with focus on learning strategies. In M. Boekaerts, P.R. Pintrich \& M. Zeidner (Eds.), Handbook of self-regulation (pp.728-747). Oxford: Elsevier Academic Press.

Wolters, C., A., Benzon, M.B., \& Arroyo-Giner, C. (2011). Assessing strategies for the self-regulation of motivation. In B.J. Zimmerman \& D.J. Schunk (Eds.), Handbook of self-regulation of learning and performance (pp. 298312). New York, NY: Routledge.

Zimmerman, B.J., \& Martinez-Pons, M. (1988). Construct validation of a strategy model of student self-regulated learning. Journal of Educational Psychology, 80, 284-290. doi: http://dx.doi.org/10.1037\%2F\%2F0022-0663.80.3.284

Zimmerman, B.J., \& Risemberg, R. (1997). Becoming a self-regulated writer: A social cognitive perspective. Contemporary Educational Psychology, 22, 73-101. doi: http://dx.doi.org/10.1006\%2Fceps.1997.0919 


\section{Appendix A}

Examples of items included in each scale

\section{Examples}

\section{Environmental Processes}

Str. \# 1. Environmental structuring

Str. \# 2. Help seeking

I try to write in quiet places.

I ask others for help if I need to do a writing task.

\section{Behavioural Processes}

Str. \# 3. Self-monitoring

I write a list of everything I should do to complete my writing task.

Str. \# 4. Self-consequating

I take a break when I finish a writing task.

Str. \# 5. Self-verbalising

I say the teacher's instructions in my own words in order to complete a writing task.

\section{Personal Processes}

Str. \# 6. Time planning

I establish a specific time to do a writing task.

Str. \# 7. Self-evaluating

I think about whether I did my best after finishing my text.

Str. \# 8. Planning

Str. \# 9. Revising

I decide which ideas I want to develop before I start writing.

I improve my text by changing some parts (e.g. add, remove and rearrange).

Str. \# 10. Organising

I write an introduction to present the topic.

Str. \# 11. Reader's awareness

I imagine who might read my text before I start writing.

Str. \# 12. Recalling/creating

I visualize the ideas which I am writing about as I write. mental images

From : Malpique \& Veiga Simão (2015) 